MRI FOLLOWING SEVERE PERINATAL ASPHYXIA 59 Maja Steinl in, Markus Good, Ernst Mart in, Chris Bösch, Department of Pediatrics, University of Zürich,
8032 Zürich, Switzerland

In 42 children suffering from severe perinatal asphyxia we attempted to find early prognostic signs of severe hypoxicischemic brain injury with MRI. We performed 14 early (first week), 24 interinediate (second to fourth week) and 55 late MRI (after one month) procedures on a 2.35 MR-system. Severe cerebral necrosis could be suspected by $T 2$ hyperintensity of the white matter, with blurred limits to the cortex in early MRI and was confirmed by $I 1$ hyperintensity of the cortex in internediate Severe cerebral necrosis was established at 3 tenths 9 of 10 children with this pattern showed severe follow- with this pattern showed severe cerebral palsy on follow-up. 24 children had normal late MRI or findings of uncertain pathological value. 9 children had a normal late MRI. In 8 children we could detect irregular myelination (patchy hyper intensities), which in some cases proved to be transient. In 5 children liquorspaces were enlarged, suggesting minimal atrophy. In two children late MRI were refused. of these 24 children none developed severe cerebral palsy or marked mental retardation. Two children showed focal ischemic lesions, six had intracranial hemorrhages. The children did not differ in the severity of their perinatal history and findings, suggesting that MRI in the first 3 months is of significant prognostic value. Supported by Swiss National Foundation 32-954388, and 3824-0.87

MHAT INFLUENCES A MOTHER'S PERCEPTION OF HLR BABY? Michael Weindling, Karina Lambrenos, Anthony Cox,

60 Rachel Calam.

Departments of Child Health and Child Psychiatry University of Liverpool, Liverpool L7 7BN, U.K.

Adverse experiences during and after pregnancy, together with information given by doctors, may lead mothers to perceive their premature babies as "difficult". 32 mothers were told that their infants were likely to develop cerebral palsy (CP), and half were randomly assigned to physiotherapy before developing motor abnormalities. Mothers of 41 matched infants without brain abnormality were told that their children's outcome was likely to be normal. At 6 weeks post-term a mother's feelings about her pregnancy and perinatal period were assessed. A standard Malaise Inventory and Bates's Infant Temperament Questionnaire were also completed.

8 mothers from each group regarded their babies as "difficult". This was not associated with obstetric complications, the birth, postnatal events or the infant's prognosis but was associated with the mother's current mental health (p:0.05). Early introduction of physiotherapy for infants at high risk of $C P$ was associated with the infant being perceived to be easier than average $(8 / 16 \vee 1 / 16, p=0.008)$

A mother's perception of her child was adversely arfected by depression, but improved by the early involvement of a supportive
professional.

HIGH-DOSE PHENOBARBITAL TREATMENT TO PREVENT POSTASRHYXIAL BRATN DAMAGE: A 6-YEAR FOLLOW-UP

61 Vineta Ruth, Marit Korkman, Annukka Liikanen, Ritva Paetau - Children's Hospital, University of Helsinki, 00290 Helsinki, Finland.

Ain: To evaluate in a randomized controlled trial if high-dose phenobarbital (PB) improves outoome after severe asphyxia. Patients: Newbom infants with a 5-min Apgar soore 0-3 or need for ventilatory assistance $>30 \mathrm{~min}$ after birth allocated to the treatment (PB+, $n=21$ mean gestational age 38.6. SPM 0.6 wh) or ontrol (Poup (PB, n=17, 38.7, 0.6 wk). Intervention: $P B 30 \mathrm{mg} / \mathrm{kg}$ was given iv before the age of $4 \mathrm{~h}$, a second dose $15 \mathrm{mg} / \mathrm{kg}$ iv 4 h later to reach a serum level of $200-300 \mathrm{~mol} / 1$, thereafter $5 \mathrm{mg} / \mathrm{kg} / \mathrm{d}$ for 5 days.

Follow-up results: of the $21 \mathrm{~PB}+$ infants, there were 4 rwonatal deaths, 4 CP (1 late death), and of the 17 PB- inf deaths, 2 CP (NS). At 6 yrs of age, the mean IQ (WISC- $x$ ) was 108 (958CI: 99-117) in PBt and 111 (97-125, NS) in PB- testable infants. The groups performed similarly in the neunopsychological tests: oppying design (VMI), attention and psycholotion confrontation naming (NEPSY). Including all outcome criteria on a quality-of-life scale ranging fom 0 (dead) to 1 (perfect health), the mean soore in PBt infants (0.500; $958 \mathrm{Cr}: 0.328$ $0.672)$ did not differ from PB- $(0.559 ; 0.368-0.750)$ infants. Conclusion: PB does not prevent postasphyxial brain damage.
ATRIAL NATRIURETIC PEPTIDE (ANP) IN PRETERM INFANTS WITH RESPIRATORY DISTRESS SYNDROME(RDS) TREATLD

62 With SURFactant.

Weir FJ, Littleton $P$, Carter $N$, Hamilton $P A$

Department of Child Health, St. George's Hospital Medical School, Cranmer Terrace, London SW 17 ORE. Dramatic but transient improvements in oxygenation may be seen after surfactant therapy. An increase in patent ductus arteriosus (PDA) may be a complication of this treatment. To see if surfactant (curosurf, CSRF) increases lent to right PDA shunting, plasma ANP levels were taken before and within 1 hour of CSRF. 12 infants, birtlweights $0.27-3.10 \mathrm{~kg}$, gestational age 25-36 weeks, received 1-5 doses of CSRF each at 12 hour intervals. The median ANP level rose progressively for doses 1,2 and 3 being 492, 955 and $2161 \mathrm{pg} / \mathrm{mI}$ respectively. In infants without a PDA, the ANP did not change significantly with CSRF (median before $605,825 \mathrm{pg}$ / $\mathrm{ml}$ after). But in those with a PDA, ANP rose sicnificantly (median before 1672, 2716pg/ml after)(p<0.01, Wilcoxon ranked sun: test) The progressively rising ANP levels during treatment to the range previously reported for infants with a PDA(1) suggest increasing left atrial distension which may be the result of ler't to right shunting through a PDA. The rise in ANP levels after CSR may be the result of increased PDA shunting due to a fall in pulmonary artery pressure. CSRF treatment appears to have significant (1) Weir haemodynamics in preterm infants.

(1) Weir et al. Pediatr Res 1990;28:292

\section{ENERGY, METABOLISM/NUTRITION}

A CHANGE IN DIETARY FAT COMPOSITION IMPROVES SERUM CHOLESTEROL VALUES IN 7 TO 13 MONTH OLD

\section{$63.1 N F A$}

63 Helena Kovanen, Eero Jokinen, Asta Myyrinmaa, Pia Salo, Tapani Rönnemaa, Jorma Viikari, llkka Välimäki and Olli

Simell - Cardioresp. Research Unit, Depts of Pediatrics and Medicine, University of Turku, and Rehabilitation Research Center of the Sociai insurance Institution, Turku, Finland

We studied how a small change in dietary fat composition influences serum total and HDL cholesterol (CHL) in healthy infants between 7 and 13 mo of age in voluntary families (intervention group, $\mathrm{N}=21$; controls, $\mathrm{N}=22$ ). Families in the intervention group received intensive health education and individualized dietary advice at 1 to 3 mo intervals. The child's diet contained $37 \mathrm{E} \%$ fat, with saturated, mono- and polyunsaturated fats at $1: 1: 1$ (controls $40 \mathrm{~F} \%$ fat; $1,5: 0,5 \cdot 0,5$ ). Serum $\mathrm{CHL}$ decreased in the intervention group from $4.3 \pm 0.4$ at 7 mo to $3.9 \pm 0.5$ $\mathrm{mmol} / \mathrm{l}$ at $13 \mathrm{mo}(P<0.05)$, but remained unchanged in the controls $(4.2 \pm 0.6$ at $7 \mathrm{mo}, 4.1 \pm 0.6$ at $13 \mathrm{mo})$. Serum HDL CHL. was stable in both groups. Apolipoprotein $B$ decreased in the intervention group from $0,71 \pm 0,2$ at $7 \mathrm{mo}$ to $0,60 \pm 0,1$ at $13 \mathrm{mo}$ (n.s.). All children grew well. We conclude that a minor modification of dietary fat composition decreases cholesterolemia in infants without obvious side effects.
64

OXIDATIVELY MODIFIED HUMAN LOW DENSTTY LIPOPROTEINS (LDLO $X$ ) INDUCE LEUKOCYTE ADHESION TO VASCULAR ENDOTHELIUM OF HAMSTERS IN VIVO. FISH OIL DIET INHIBITS THIS EFFECT. Christoph Hübner", Hans-Anton Lehr* Konrad Messmer and Alfried Kohlschütter*

Department of Pediatrics^, University of Hamburg, D 2 Hamburg 20 and Institute for Surgical Research. University of Kunich, D-8 Müchen 70 , Germany.

Adhesion of leukocytes to the microvascular endothelium is a common feature in disorders such as ischemia-reperfusion injury and complications of bone marrow transplantation. Using intravital fluorescence microscopy in a skinfold chamber model in hamsters. we found that injection of human LDLox initiated leukocyte adhesion to microvascular endothelium while native LDL did not ( $\mathrm{p}<0.01)$. After a fish oil diet, arachidonic acid (AA) was largely replaced by eicosapentaenoic acid (EPA) in leukocytes, and the
adhesion effect of LDLox was inhibited ( $<0.01)$. adhesion effect of LDLox was inhibited ( $<<0.01$ ).
Leukotriene (LT) B4, the lipoxygenase product of AA is a potent chemotactic mediator, whereas LTB5, the EPA product, is weakly chemotactic. We suggest that LDLo $x$ initiate adhesion of leukocytes to microvascular endothelium by promoting LTB synthesis and that fish oil diet inhibits this LDLox effect. 